\title{
Diagrams Present in the Resolution of Problems of Multiplicative Comparison with High School Students
}

\author{
Fany M. González Barrios \\ Specialized University of Las Americas-Panama, Las Tablas, Los Santos 0701, Panama
}

\begin{abstract}
The purpose of this study is to identify the use (or not) of diagrams when solving problems of multiplicative comparison in eighth-grade students of the Rafael Antonio Moreno secondary school located in Macaracas, province of Los Santos-Panama. The methodology used is mixed and descriptive with a non-experimental design. As an instrument, a written test consisting of two parts (part a and part b) is prepared, which is applied to eighth-grade students who take the mathematics subject of said study center.
\end{abstract}

Key words: Problem solving, diagrams, multiplicative comparison.

\section{Introduction}

This research has been carried out in Los Santos-Panama, based on a similar study conducted by González and Castro since 2014 in Granada-Spain in order to observe if the same behavior shown in this study is persistent in relation to this.

This study is a small study as part of a larger study that tries to investigate the type of diagrams that high school students use when solving problems of multiplicative comparison. In the educational curriculum of Panama, there is no module for the development of problems of multiplicative comparison, however, it is common to find everyday life situations that lead to the emergence of this type of problems. While it is true that these problems are presented in the first years of high school within other content determined in Panamanian academic curricula, the so-called Comparison Problems appear in the United States as part of the curricula itself [1].

For Ref. [2] the difference between reading an algebraic resolution or not is in the intention to use the unknown quantities as known and operate with them.

Corresponding author: Fany M. González Barrios, Doctor in Mathematics Didactic, research field: numerical and algebraic thinking.
The reading can be arithmetic although the resolver uses letters as auxiliary variables for the sole purpose of obtaining its value in a ternary arithmetic expression in which two of the three quantities are known. In a study similar to this, González, Castro-Rodríguez, and Castro [3] show that students are not familiar with the construction of diagrams that integrate the existing relationships in the problem statement. Many of the students do not use all the information contained in the statement and draw diagrams alluding to the theme or the context of the statement without relating the data of the same.

That is why this study has been proposed, to show the use of diagrams in the resolution of mathematical problems by Panamanian students.

\section{Experimental Section}

\subsection{Method}

A total of 34 eighth-grade students from a public education center in the city of Macaracas in Los Santos, Panama, are given individual pen and paper tests. It consists of two sections ( $\mathrm{a} \& \mathrm{~b}$ ), in the section "a" students are asked to solve a multiplicative comparison problem presented verbally and written and in the "b" section they are asked to build a diagram that represents the statement of the problem. 


\subsection{Research Objectives}

\subsubsection{General Objective}

- Analyze the types of diagrams that students build when solving multiplicative comparison problems.

\subsubsection{Specific Objectives}

- Identify the types of diagrams that students build.

- Categorize the different diagrams that students build.

- Carry out an analysis of the different types of diagrams.

\subsubsection{Hypothesis}

- The high school students of the Rafael Moreno School construct diagrams when solving multiplicative comparison problems. Instruments and/or data collection techniques and/or materials and/or equipment and/or inputs and/or infrastructure will be enhanced.

The design of a questionnaire previously developed by the author has been used, consisting of six problems of multiplicative comparison of unknown referent, detailed in Ref. [4] with two sections (a and b) each, to be applied to eighth-grade students of the Rafael Moreno School in Macaracas, Los Santos.

The problems contained in this questionnaire are aimed at exploring the individual performance of students in solving multiplicative comparison problems presented with verbal, symbolic or graphic statements and the interpretation they show in each case.

With the help of the statistical program Max. QDA the data are processed and analyzed to generate the results.

\section{Results and Discussion}

\subsection{Results}

The written test that has been applied individually to the eighth-grade students of the Rafael Antonio Moreno School in Macaracas, Los Santos contains only the analysis of the results of Block 1, corresponding to tasks $1 \mathrm{a}$ and $1 \mathrm{~b}, 2 \mathrm{a}$ and $2 \mathrm{~b}$. Let us see Table 1.

As shown in Table1, in Block 1 there are two tasks (task 1 and task 2) with two sections each (1a and 1b; $2 \mathrm{a}$ and $2 \mathrm{~b}$ ) and to distinguish tasks from one another we place the digit corresponding to the task and the letter of the section, depending on whether it corresponds to section $\mathrm{a}$ or $\mathrm{b}$; that is, if we are going to analyze task 2 of section $b$, we place $2 b$ and so on in each case.

In this block, the tasks are verbal statements. It is worth remembering that the problems in this block are 1 and 2.

For each of the two tasks, we have jointly analyzed the students' answers in the two corresponding sections (1a with $2 \mathrm{a}$ and $1 \mathrm{~b}$ with $2 \mathrm{~b}$ ), in order to categorize the productions from the verbal, symbolic and graphic point of view.

For purposes of this work, we have considered the two general phases used by Ref. [5] which are: understanding the problem and solving the problem, as shown in Fig. 1.

Fig. 1 is phases of solving verbal problems, taken from Ref. [5].

In this study, we consider only the comprehension phase with the two sub-steps (translation and integration), independently if they make calculation errors or not.

Finally, we have taken the 6 categories presented by Ref. [4], of which we show examples of them with the exception of those answers that do not have a record.

Table 1 Problems posed to students.

\begin{tabular}{|c|c|c|c|}
\hline & Statement & Questions & Code \\
\hline Block 1 & $\begin{array}{l}\text { 1. In a train } 4 \text { times as many passengers travel as in a } \\
\text { bus. } 64 \text { passengers travel on a train. How many } \\
\text { passengers travel in a bus. }\end{array}$ & $\begin{array}{l}\text { a) solve the problem } \\
\text { b) draw a diagram that relates the } \\
\text { statement data. }\end{array}$ & $\begin{array}{l}1 \mathrm{a} \\
1 \mathrm{~b}\end{array}$ \\
\hline & $\begin{array}{l}\text { 2. Isabel saved } 287 \text { euros. She saved } 7 \text { times as much as } \\
\text { Eva saved. How much did Eva save? }\end{array}$ & $\begin{array}{l}\text { a) solve the problem } \\
\text { b) draw a diagram that relates the } \\
\text { statement data }\end{array}$ & $2 \mathrm{a}$ \\
\hline
\end{tabular}

Taken from Ref. [6]. 


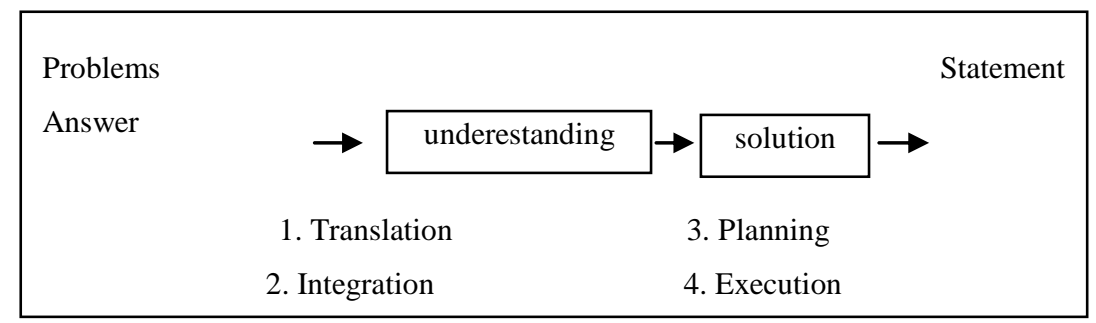

Fig. 1 Phases of problem solving.

Taken from Ref [5]

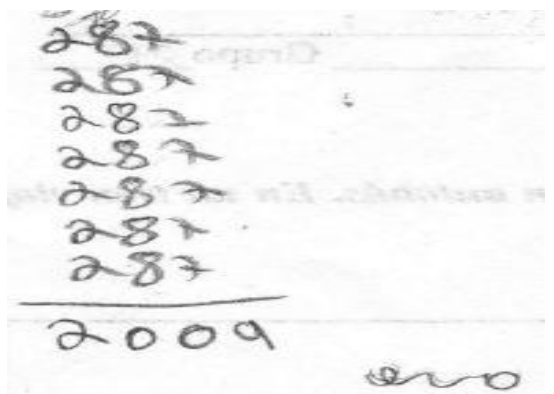

Fig. 2 Problem solving by secondary student.

- R0: there is no information/no resolution process; the student does not produce any type of written record, leaves the space blank and does not present a resolution process.

- REA: additive error; the student uses addition or subtraction instead of multiplication or division, that is, the student interprets the problem as if it were an additive structure, using addition or subtraction to solve it.

Example: the student, called E-16, solves the section by placing 7 times the same number and at the end adds the total.

Table 2 shows a summary of the frequencies and percentages obtained from the students' productions in each category for this section.

From this table you can comment:
The 68 answers (correct and incorrect) have been arithmetically produced without using a diagram to address the solution in both multiplicative comparison tasks.

A total of 40 correct answers are observed, if we take into account as correct the categories REIR and $\mathrm{RC}$, which represents $58.8 \%$, having greater success in the task 1 , than in task 2.

The type of error that is committed with greater frequency is that of reverses, $33.8 \%$.

In task 2 , there are a greater number of reverse errors.

It is observed that no student uses algebraic representation to solve this type of problems, despite having recent knowledge of algebra.

Section b (diagram drawing)

DCL: qualitative drawing. There are drawings of characters or objects alluding to the theme or the context of the statement.

Image 1. Student E-8 makes a Qualitative Drawing in which he only builds the train.

DCNI: integrated quantitative diagram.

Image 2. The student E-29 builds an integrated quantitative diagram, relating the data of the problem statement.

Table 2 Frequencies of section a of Block 1.

\begin{tabular}{llllll}
\hline \multicolumn{2}{l}{ Frequencies Percentages } & & & \\
\hline Category & Description & $1 \mathrm{a}$ & $2 \mathrm{a}$ & Total & $\%$ \\
\hline R0 & Blank/without resolution process & 1 & 0 & 1 & 1.47 \\
REA & Additive error & 0 & 4 & 4 & 5.89 \\
REI & Reverse error & 6 & 17 & 23 & 33.82 \\
REIR & Reverse error with rectification & 0 & 1 & 1 & 1.47 \\
RC & Correct arithmetic representation & 27 & 12 & 39 & 57.35 \\
RAC & Correct algebraic representation & 0 & 0 & 0 & 0.00 \\
& Total & 34 & 34 & 68 & 100.00 \\
\hline
\end{tabular}




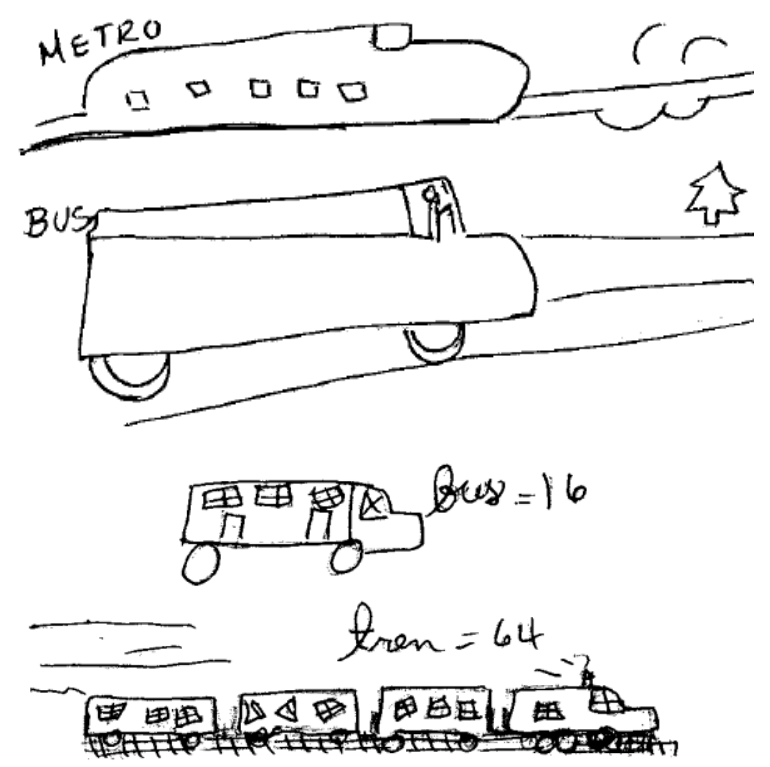

Fig. 3 Diagrams by secondary student.

Table 3 Diagrams constructed by students.

\begin{tabular}{llllll}
\hline \multirow{2}{*}{ Category } & \multicolumn{5}{l}{ Frequencies and percentages } \\
\cline { 2 - 6 } & Description & $1 \mathrm{~b}$ & $2 \mathrm{~b}$ & Total & \multicolumn{1}{l}{} \\
\hline D0 & Without drawing/blank & 1 & 1 & 2 & 2.94 \\
DRE & $\begin{array}{l}\text { Reformulation of the } \\
\text { statement }\end{array}$ & 0 & 0 & 0 & 0.00 \\
DEP & Schematic expression & 0 & 0 & 0 & 0.00 \\
DCL & Qualitative drawings & 27 & 30 & 57 & 83.82 \\
DCN & Quantitative diagrams & 4 & 3 & 7 & 10.30 \\
DCNI & Integrated quantitative & 2 & 0 & 2 & 2.94 \\
& diagrams & 34 & 34 & 68 & 100.00 \\
\hline
\end{tabular}

We have considered the categorizations used in previous studies [7].

In this section $\mathrm{b}$ in problems 1 and 2 , students are asked to draw a diagram starting from the problem stated verbally.

From the frequency table, it can be expressed:

Blanks production is about 3\%, which we assume as familiarity with these verbal problems.

The highest frequency is in the production of qualitative diagrams (84\%).

The frequency with which they make quantitative drawings that integrate the data present in the statement of the problems in section $1 b$ is greater than in section $2 b$, this leads us to think that section $1 b$ is easier to represent quantitatively than section $2 b$.

\section{Conclusions}

One of the purposes of this study is to detect whether students use diagrams when solving arithmetic problems of multiplicative comparison and what types of graphic representation they use in relation to the multiplicative comparison.

In this sense, the hypothesis of the study has not been corroborated, since the students do not need the use of diagrams when solving multiplicative comparison problems.

Regarding the type of diagram they build, within the category used by Ref. [6], the presence of mostly qualitative drawings is shown, and a scarce presence of quantitative diagrams that integrate the data of the verbal statement of the problem.

Students solve problems correctly or not, without leaving blanks, which leads us to conclude that these problems are approachable.

No case of algebraic form is presented in the solution of the problems, despite having received an introduction to algebra two weeks before the study, which leads us to conclude that students in this level maintain an arithmetic mindset instead of algebraic.

There are even cases where high school students maintain the additive structure instead of using multiplication. As they show [7], the use of real situations contributes to the students distinguishing a multiplicative situation from an additive.

\section{Acknowledgments}

To the National Secretariat of Science and Technology (SENACYT-Panama) and to the Specialized University of the Americas-Azuero Extension.

\section{References}

[1] Jitendra, A. K. 2002. "Teaching Students Math Problem-Solving through Graphic Representations." Teaching Exceptional Children 34 (4): 34-8.

[2] Huerta, M., Edo, I., Amorós, R., and Arnau, J. 2016. “Un esquema de codificación para el análisis de las resoluciones de los problemas de probabilidad 
condicional." Revista Latinoamericana de Investigación en Matemática Educativa 19 (3): 335-62. http://dx.doi.org/10.12802/relime.13.1934.

[3] González, F. M., Castro-Rodríguez, E., and Castro, Y. E. 2016. "Interpretación de diagramas de comparación multiplicativa por estudiantes de secundaria." PNA 10 (4): 280-306.

[4] Castro, F. M., and González, Y. E. 2012. "Diagramas integrados producidos por estudiantes de ESO en la resolución de problemas de comparación multiplicativa." In Investigación en Educación Matemática XVI, edited by A. Estepa, Á. Contreras, J. Deulofeu, M. C. Penalva, F. J. García and L. Ordóñez. Jaén: SEIEM, pp. 313-22. ISSN:
1888-0762.

[5] Castro, E. 1994. "Niveles de comprensión en los problemas verbales de comparación multiplicativa." Tesis Doctoral, Universidad de Granada.

[6] Castro, F. M., and González, Y. E. 2014. "Diagrams Produced by Secondary Students in Multiplicative Comparison Word Problems." Journal of Mathematics and System Science 4 (2): 83-92.

[7] Fernández Verdú, C., and Llinares Cisca, S. 2010. "Relaciones entre el pensamiento aditivo y mutiplicativo en estudiantes de educacion primaria. el caso de la construcción de la idea de razón." Horizontes Educacionales 15 (1): 11-22. 